\title{
Metal Water-Sediment Interactions and Impacts on an Urban Ecosystem
}

\author{
Lian Lundy *, Luciana Alves, Michael Revitt and Dirk Wildeboer \\ Department of Natural Sciences, Faculty of Science and Technology, Middlesex University, The Burroughs, \\ Hendon, London NW4 4BT, UK; L.Alves@mdx.ac.uk (L.A.); M.Revitt@mdx.ac.uk (M.R.); \\ D.Wildeboer@mdx.ac.uk (D.W.) \\ * Correspondence: 1.lundy@mdx.ac.uk
}

Academic Editor: Susanne Charlesworth

Received: 26 May 2017; Accepted: 30 June 2017; Published: 5 July 2017

\begin{abstract}
The EU Water Framework Directive (WFD) requirement that all surface water bodies achieve good ecological status is still a goal for many regulatory authorities in England and Wales. This paper describes field and laboratory studies designed to identify metal contaminant loadings and their distributions within water bodies located in the Lower Lee catchment (London, UK). Water and sediment samples have been collected from increasingly urbanised sites on the River Lee and its main tributaries over a two-year period with samples analysed for total concentrations of cadmium, copper, lead, mercury, nickel, tin, and zinc. Complimentary batch tests indicate a positive relationship between aqueous metal concentrations and the batch test-derived sediment metal release data, particularly during wet weather events. Field data indicate a dynamic relationship between water and sediment concentrations with both being capable of exceeding relevant environmental quality standards/sediment quality guidelines at all sites. Mean sediment metal concentrations across all sites were found to be highest for $\mathrm{Cu}\left(141.1 \pm 111.0 \mu \mathrm{g} \mathrm{g}^{-1}\right), \mathrm{Pb}\left(175.7 \pm 83.0 \mu \mathrm{g} \mathrm{g}^{-1}\right)$, and $\mathrm{Zn}$ $\left(499.9 \pm 264.7 \mu \mathrm{g} \mathrm{g}^{-1}\right)$ with $\mathrm{Zn}$ demonstrating elevated mean water concentrations $\left(17.2 \pm 13.8 \mu \mathrm{g} \mathrm{L}^{-1}\right)$ followed by $\mathrm{Ni}\left(15.6 \pm 11.4 \mu \mathrm{g} \mathrm{L}{ }^{-1}\right)$ and $\mathrm{Cu}\left(11.1 \pm 17.8 \mu \mathrm{g} \mathrm{L}^{-1}\right)$.
\end{abstract}

Keywords: diffuse and point source pollution; urban receiving waters; urban sediment quality

\section{Introduction}

The European Union (EU) Water Framework Directive [1] established a framework for water protection and management with the objective that surface and ground waters in all member states should achieve good ecological and chemical status by 2015 followed by two six-year cycles to allow further development of river basin management plans. A total of 45 substances, including five metals, have been identified as being of particular concern with 24 of them (including $\mathrm{Ni}$ and $\mathrm{Pb}$ ) classified as priority substances (PS) and 21 designated as priority hazardous substances (PHS; including Cd, $\mathrm{Hg}$ and Sn (as tributyltin)) [2]. Pollutants classified as PS were required to meet Environmental Quality Standards (EQS) by 2015 with a PHS designation signifying that emissions of these substances to water need to cease. However, in 2015 within the Thames river basin district, which incorporates the River Lee catchment, it was reported that $45 \%$ and $17 \%$ of water bodies continued to be affected by point pollution discharges of wastewater and urban diffuse pollution, respectively [3].

The Lower Lee catchment has a long history of water quality problems as a consequence of increasing urbanisation associated with factors, such as discharges from both point sources (wastewater treatment plants (WWTPs)), industry, commercial enterprises), diffuse sources (e.g., runoff from roads and associated urban surfaces), navigation, and water abstraction $[4,5]$. Wastewater discharges have been heavily implicated in the failures of surface water quality to comply with EQS with, for example, $34 \%$ of Ni originating from domestic sewage, compared with $25 \%$ from runoff 
sources [6]. This difference has the potential to be greater when industrial wastewaters are discharged to municipal WWTPs.

In polluted waters, many contaminants are predominantly adsorbed to suspended particles in the water column and to sediments settled on the river bed. This identifies sediments not only as pollutant sinks but also as potential sources of contamination as a result of changes in environmental conditions and/or anthropogenic disturbances. Sediments represent a more stable medium for tracing metal sources compared to water [7]. Whereas aqueous phase sampling provides an indication of metal concentrations on a relatively short time scale not exceeding hours, sediments can be representative of pollutant trends over longer periods, usually up to one year [7-9]. For this reason, bed sediments have been increasingly employed in the assessment of the contamination of fluvial systems in urban and suburban areas [10-14].

Sediment quality criteria are not specifically identified in the existing legislation associated with the Water Framework Directive [2], but their implications for water quality and ecosystem health are recognised [15] together with their relevance to long-term pollutant accumulation [16]. Contaminants in sediments may be mobilised by river processes (e.g., storm events, influx from groundwater and bio-turbation) or human activities (e.g., dredging, permitted and unpermitted discharges of effluents and runoff, and recreational activities), which can cause release to the overlying water column and the potential for downstream transport [17]. The spatial variability of metal content in river water and sediment depends on the ability of geochemical factors [18] and chemical parameters such as $\mathrm{pH}$, dissolved organic carbon (DOC) and redox potential [19] to influence sediment-water interactions. Tackling the risks posed by contaminated sediment represents a significant challenge which has implications for the interaction between land-based activities, management of water and protection of the wider environment and human health [20]. For these reasons, sediment EQS have been developed by individual countries, including Canada [21], The Netherlands [22] and France [23]. Duodu et al. [24] have proposed the use of a range of sediment quality indices, including the contamination factor, enrichment factor, index of geo-accumulation, modified degree of contamination, pollution index, and modified pollution index to comprehensively ascertain the sediment quality.

Rivers represent key resources in terms of providing water for drinking supply, industry, and crop cultivation. Additionally, in urban catchments they are required to receive wastewater and surface runoff discharges whilst maintaining recreational and conservation facilities. This paper investigates the ability of the lower River Lee, an important urban river in North East London, to fulfil these functions through a study of the spatial and temporal trends in the metal levels in both sediments and the overlying waters. Seven metals $(\mathrm{Cd}, \mathrm{Cu}, \mathrm{Pb}, \mathrm{Hg}, \mathrm{Ni}, \mathrm{Sn}$, and $\mathrm{Zn})$ have been monitored to obtain a better understanding of how sediment-water interactions can influence their distribution and hence their impact on the urban river environment.

\section{Materials and Methods}

\subsection{Sampling Sites and Sample Collection}

The waterways within the Lower Lee catchment serve as sources of water supply for London, recipients for treated sewage discharges, navigation channels, as well as providing recreational and environmental resources. The catchment drains an area of $367.4 \mathrm{~km}^{2}$ in which the geology consists of London clay with deposits of alluvium and river gravels, overlying chalk. Consequently, the river levels can peak rapidly during high rainfall events leading to the potential for flooding.

Water and sediment samples were collected from five progressively urbanising sites (labelled A to E; see Table 1 and Figure 1) on eight occasions between November 2014 and March 2016. An Ekman grab was used for sediment collection and surface water samples were obtained using a polypropylene dipper fitted with a $500 \mathrm{~mL}$ cup. Collected water samples were immediately transferred to $500 \mathrm{~mL}$ acid-washed plastic bottles and stored in ice during transfer to the laboratory and storage at $4{ }^{\circ} \mathrm{C}$ prior to preparation for analysis. Surficial bottom sediments were returned to the laboratory on ice for oven 
drying overnight at $105{ }^{\circ} \mathrm{C}$. Prior to extraction the dried samples were gently ground and sieved to particle sizes $\leq 1 \mathrm{~mm}$. In association with sample collection, in situ measurements of temperature, dissolved oxygen (DO) and $\mathrm{pH}$ were obtained.

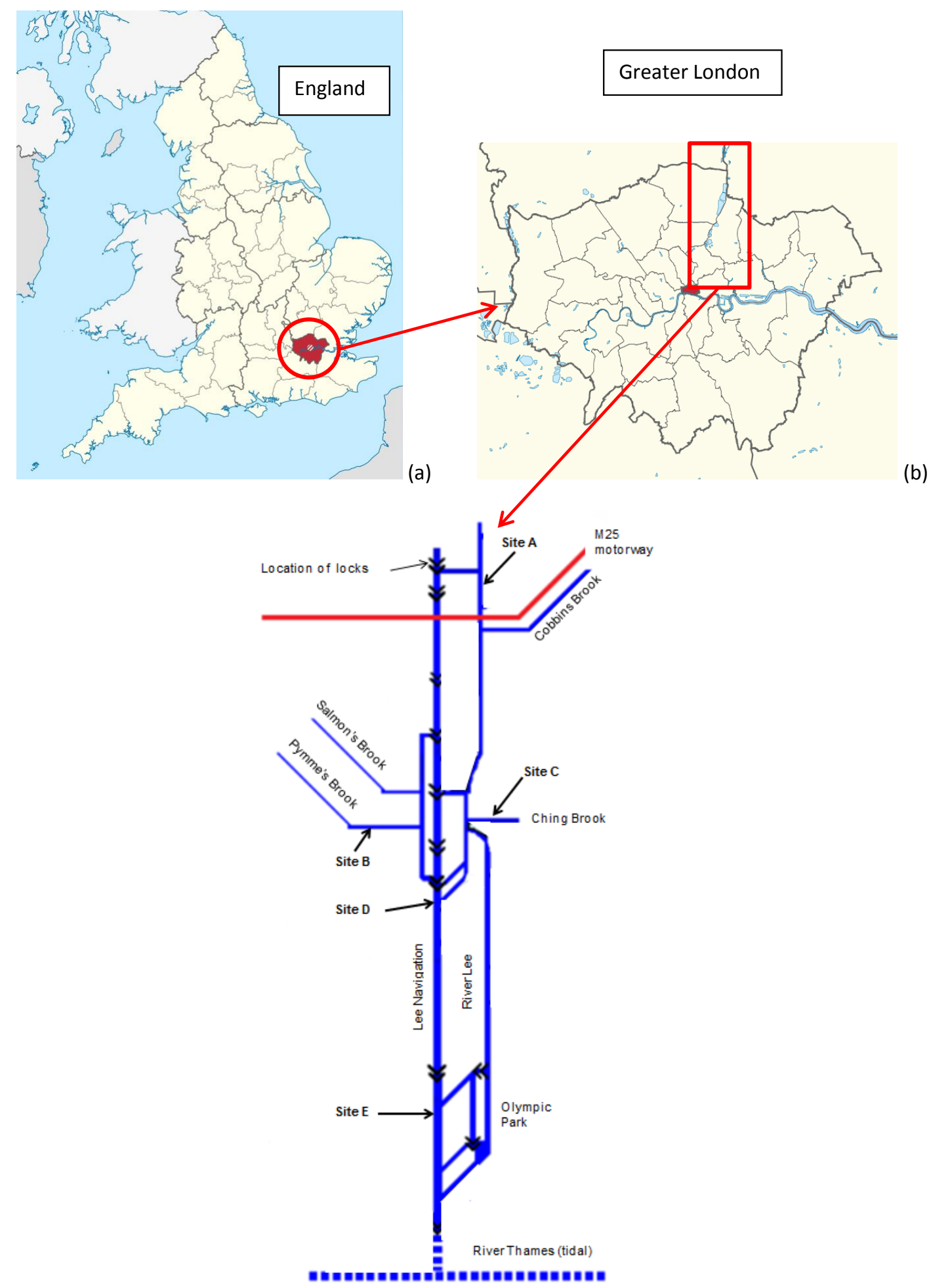

(c)

Figure 1. Location maps $(\mathbf{a}, \mathbf{b})$ and schematic identifying location of sampling sites on the Lower River Lee (c). 
Table 1. Location of sampling sites in the Lower Lee catchment.

\begin{tabular}{cl}
\hline Site & \multicolumn{1}{c}{ Description of Sampling Site Location } \\
\hline A & Upstream site on River Lee on northern edge of London boundary and above the M25 orbital motorway \\
\hline B & On the Pymmes Brook before its confluence with the River Lee; approaching from a westerly direction \\
\hline C & On the Ching Brook before its confluence with the River Lee; approaching from an easterly direction \\
\hline D & $\begin{array}{l}\text { On the River Lee before separation into the Lee Navigation Channel; at a mid-point down the Lower } \\
\text { Lee Catchment }\end{array}$ \\
\hline E & On the lower reaches of the River Lee prior to its confluence with the River Thames \\
\hline
\end{tabular}

\subsection{Batch Tests}

The procedure for the batch tests was adapted from that described by the Organisation for Economic Co-operation and Development (OECD) guidelines [25]. The tests were conducted in duplicate, for each of the five monitored sites, in $1 \mathrm{~L}$ sealed and light-excluded sterile bottles using a ratio of sediment $(30 \mathrm{~g}$ dry weight) to river water $(900 \mathrm{~mL})$. After an initial stabilisation period of $24 \mathrm{~h}$, stirring was initiated using polytetrafluoroethylene (PTFE) coated magnetic stirring bars. After stirring for $24 \mathrm{~h}$ a $2 \mathrm{~h}$ period of settling was allowed. Subjecting the supernatant to a centrifugal force of $3060 \times g$ for $10 \mathrm{~min}$ provided water samples for analysis as described in Section 2.3. Measurements of $\mathrm{DO}, \mathrm{pH}$ and temperature in the water column were taken throughout the batch tests.

\subsection{Laboratory Analysis}

Water and sediment samples were subjected to microwave digestion (MARS press; CEM Corporation, Matthews, USA) according to an adaptation of US EPA methods 3015A [26] and 3051A [27]. Water samples $(27 \mathrm{~mL})$ were placed in pre-cleaned PTFE-TFM digestion vessels followed by the addition of concentrated $(70 \%)$ nitric acid $(2 \mathrm{~mL})$ and concentrated hydrochloric acid $(1 \mathrm{~mL})$. Deionised water $(27 \mathrm{~mL})$ was used as the reagent blank. The vessels were sealed and after microwave digestion each water sample was filtered through Whatman ash-less, grade 42 filter papers and diluted to $50 \mathrm{~mL}$ using deionised water. All glassware was soaked overnight in $10 \%$ nitric acid, rinsed with deionised water, and oven dried prior to use. Extracted water samples were analysed for metals using ICP-MS (X-Series 2, Thermo Fisher Scientific, Hemel Hempstead, UK). Instrument detection limits, calculated as three times the standard deviation of the blank, were $9.2 \mathrm{ng} \mathrm{L}^{-1}, 29.4 \mathrm{ng} \mathrm{L}^{-1}$, $223.7 \mathrm{ng} \mathrm{L}^{-1}, 75.1 \mathrm{ng} \mathrm{L}^{-1}, 7.3 \mathrm{ng} \mathrm{L}^{-1}, 22.9 \mathrm{ng} \mathrm{L}^{-1}$, and $47.7 \mathrm{ng} \mathrm{L}^{-1}$ for $\mathrm{Cd}, \mathrm{Cu}, \mathrm{Hg}, \mathrm{Ni}, \mathrm{Pb}, \mathrm{Sn}$, and $\mathrm{Zn}$.

Sediment samples (accurately weighed to approximately $0.5 \mathrm{~g}$ ) were extracted in pre-cleaned PTFE-TFM digestion vessels using concentrated $(70 \%)$ nitric acid $(9 \mathrm{~mL})$ and concentrated hydrochloric acid ( $3 \mathrm{~mL}$ ). An analytical reagent blank was prepared using the acids only. After microwave digestion and subjecting to a centrifugal force of $3060 \times \mathrm{g}$ for $10 \mathrm{~min}$, the supernatant was transferred to a volumetric flask, and together with washings, made-up to a volume of $100 \mathrm{~mL}$ with deionised water. The metal concentrations of all sediment samples were determined using ICP-OES (iCAP 6000, Thermo Fisher Scientific). Instrument detection limits were $0.3 \mathrm{ng} \mathrm{g}^{-1}, 0.8 \mathrm{ng} \mathrm{g}^{-1}, 0.8 \mathrm{ng} \mathrm{g}^{-1}, 0.4 \mathrm{ng} \mathrm{g}^{-1}$, $1.0 \mathrm{ng} \mathrm{g}^{-1}, 1.3 \mathrm{ng} \mathrm{g}^{-1}$, and $0.2 \mathrm{ng} \mathrm{g}^{-1}$ for $\mathrm{Cd}, \mathrm{Cu}, \mathrm{Hg}, \mathrm{Ni}, \mathrm{Pb}, \mathrm{Sn}$, and $\mathrm{Zn}$. Using a certified reference material (SQC001 (Lot 011233), Sigma-Aldrich, Poole, UK), recovery efficiencies from sediment samples of between $81.1 \%$ for $\mathrm{Ni}$ and $96.5 \%$ for $\mathrm{Zn}$ were determined. Multi-element calibration standards of $0.1,0.5,0.75$, and $1 \mathrm{mg} \mathrm{L}^{-1}$ were prepared for sediment analyses with the six standards for water analyses covering the concentration range of $2-20 \mu \mathrm{g} \mathrm{L}^{-1}$. All analyses were carried out in triplicate and daily performance checks were conducted on each instrument prior to commencement of analyses. The instrument calibrations were checked every 10 samples throughout the analytical procedure by running one of the calibration solutions as an unknown. Recalibration was performed if drifts in the calibration measurements exceeded $10 \%$. The precision of the methodology (\% RSD) for water extractions was typically $<15 \%$ for all metals, but improved to $<5 \%$ for sediment extractions, except for $\mathrm{Sn}$ where it was $<10 \%$. 


\section{Results and Discussion}

\subsection{Concentrations of Selected Metals and Associated Parameters in Surface Waters}

The concentrations of selected metals in surface waters collected at the five sites over a two year period are shown in Table 2. The monitored ranges at each site show considerable variations (generally 1-2 orders of magnitude, but up to three orders of magnitude for Sn at site E), which are characteristic of sites receiving point and diffuse pollution inputs [28,29]. In comparison with an earlier study of metal pollution within the River Lee [4], mean aqueous concentrations of $\mathrm{Cd}, \mathrm{Cu}, \mathrm{Ni}, \mathrm{Zn}$ and $\mathrm{Pb}$, are generally lower and it may be that on-going pollution mitigation measures, such as modernisation of WWTPs, installation of sustainable drainage systems (SuDS), and sediment dredging have resulted in a decline in surface water metal concentrations. However, the earlier study reported comparatively lower $\mathrm{Hg}$ and Ni concentrations, suggesting specific sources of these metals have yet to be remediated. Despite the currently-observed variabilities in metal concentrations, some trends are apparent. For example, the mean and maximum metal concentrations determined in the two tributaries, site $C$ (mixed industrial-urban land use) and, particularly, site B (densely urbanised land use) (see Figure 1), consistently exceed the concentrations at the upstream site A (with the exception of $\mathrm{Hg}$ and Sn). The tributaries are shown to be important contributors of metals to the main River Lee leading to elevated mean concentrations at the highly-urbanised downstream site E. Within the main channel (sites A, D, and $\mathrm{E}$ ), mean concentrations of $\mathrm{Cd}$ and $\mathrm{Pb}$ increase in a downstream direction as would be expected due to progressively increasing urbanisation (see Table 2). However, other metals were not consistent with this trend with the highest mean concentrations of $\mathrm{Hg}$ being observed at site $\mathrm{A}, \mathrm{Cu}, \mathrm{Ni}$, and $\mathrm{Zn}$ at site $\mathrm{D}$, and $\mathrm{Sn}$ at site $\mathrm{E}$, indicating that the different sites are in receipt of multiple sources of pollutants. The elevated concentrations determined at site D are associated with the fact that it is located at the point where a WWTP discharges treated effluents into the River Lee.

Two of the eight sampling collections occurred following wet weather conditions (defined as rainfall $\geq 4 \mathrm{~mm}$ within the previous $48 \mathrm{~h}$ ). The highest mean concentrations of $\mathrm{Zn}, \mathrm{Ni}$ and $\mathrm{Sn}$ (with the exception of site A for Sn) were monitored on these occasions (May 2015 (4 mm) and August 2015 (15.2 mm)). In contrast the highest mean concentrations of $\mathrm{Cd}$ (except at Site $\mathrm{A}$ ) and $\mathrm{Cu}$ were consistently reported during a dry weather sampling event (March 2016; no rainfall within the previous $48 \mathrm{~h}$ ) indicating that the catchment is in receipt of pollutants during both dry (point source) and wet weather (diffuse) events and that some pollutants may be preferentially associated with specific sources. These results highlight the complexities associated with identifying pollutant sources in an urban catchment [5,30-32].

EU environmental quality standards (EQS) are available for $\mathrm{Cd}, \mathrm{Hg} \mathrm{Ni}$, and $\mathrm{Pb}$, and UK WFD Technical Advisory Group (TAG) standards [33] exist for Cu and Zn (see Table 2). A comparison of the determined concentrations with these standards indicate that mean concentrations of $\mathrm{Pb}$ and $\mathrm{Ni}$ exceed the annual average (AA) EQS at all sites with the maximum concentrations of $\mathrm{Cd}$ exceeding the AA value at sites B, C, D and E. Exceedance of the AA value indicates that there is a chronic threat to receiving water status. Metal concentrations greater than the maximum allowable concentration (MAC) are indicative of a short-term or acute risk to receiving water health. Mean concentrations of Hg exceed the corresponding MAC values at sites A, B, D, and E with maximum concentrations of Ni mirroring this behaviour at sites B and D. Mean concentrations of $\mathrm{Cu}$ and $\mathrm{Zn}$ exceed the appropriate UK TAG standards [33] at all sites (apart from $\mathrm{Zn}$ at site A) identifying a negative impact to the ecological status of these sites under acute and chronic scenarios. $\mathrm{DO}, \mathrm{pH}$, and temperature measurements were taken at each site at the time of sampling. Mean values over the two year monitoring period ranged from 7.2 to $8.9 \mathrm{mg} \mathrm{L}^{-1}$ (for DO), from 8.1 to 8.7 (for $\mathrm{pH}$ ) and from 12.9 to $15^{\circ} \mathrm{C}$ (for temperature), with no parameter showing a consistent trend by site location or sampling date (data not presented). Comparisons with UK TAG water quality guidelines [33] for rivers indicate that samples fall under the high category for DO and the 'high/good quality' for $\mathrm{pH}$. 


\subsection{Concentrations of Selected Metals in Surficial Sediments}

An overview of the concentrations of selected metals in surficial sediment at each of the five sites is reported in Table 3. As with surface water metal concentrations, sediment metal concentrations show considerable variation between and within sites, generally within an order of magnitude, but with concentrations of $\mathrm{Ni}$ and $\mathrm{Hg}$ varying across three orders of magnitude on some occasions. With the exception of $\mathrm{Ni}$, mean sediment metal concentrations are consistently lowest at the upstream site (site $\mathrm{A}$ ) and $\mathrm{Cd}$ and $\mathrm{Hg}$ show the expected increase through the main river channel (i.e., site $\mathrm{A}<\mathrm{D}<\mathrm{E}$ ). In contrast, mean sediment concentrations of $\mathrm{Cu}, \mathrm{Pb}, \mathrm{Sn}$, and $\mathrm{Zn}$ are highest at site $\mathrm{D}$, probably due to its location downstream of both the polluted Site B, which has been identified as contributing metals to the system) and a WWTP.

In the absence of national or international environmental quality standards for sediments, Table 3 lists the available Dutch and Canadian sediment quality guidelines. A comparison of mean concentrations with these values indicates that $\mathrm{Cu}, \mathrm{Zn}, \mathrm{Pb}$, and $\mathrm{Hg}$ exceed the Dutch target values (TV) and the Canadian interim sediment quality guideline (ISQG) value at all sites (with the exception of Site $\mathrm{A}$ for $\mathrm{Pb}$ and $\mathrm{Hg}$ in relation to the TV). Exceedance of these values indicates sediments will be unable to fully recover their functional properties (TV) and that biological impacts are expected to occur (ISQG). A comparison with the Dutch intervention value (IV; concentrations at which functional sediment properties are seriously impaired) and Canadian probable effects level (PEL; the level above which biological effects are expected to occur frequently) indicate that $\mathrm{Cu}$ and $\mathrm{Zn}$ exceed the IV at site $\mathrm{D}$ only, with all metals (except Ni) exceeding PEL values at least at one site. Four metals exceed at least one set of guideline values at sites $\mathrm{D}(\mathrm{Cu}, \mathrm{Hg}, \mathrm{Pb}, \mathrm{Zn})$ and $\mathrm{E}(\mathrm{Cd}, \mathrm{Hg}, \mathrm{Pb}$ and $\mathrm{Zn})$, indicating elevated levels of contamination, and these are, therefore, highlighted as key pollutant sinks within the system.

\subsection{Release of Sediment Metals to Overlying Waters during Laboratory Batch Tests}

Table 4 identifies the amount of metal released into the overlying water column during the batch experiment (expressed as the percentage mass of metal released into solution compared to the total amount of metal contained in the sediment). A positive metal release into overlying water occurs for sediments collected from all five sites. Although the continual stirring associated with the batch test experiments does not directly simulate the conditions encountered within the field, the results confirm the potential for sediments to release metals and highlight the need for further investigation of the influencing conditions. This is particularly important with respect to the development and implementation of programmes of measures to achieve good ecological status under the EU WFD [1,34,35]. Whilst the amount of metal released into the sediment varies between metals and sites, the level of variation is generally within an order of magnitude, ranging from a low of $0.12 \%$ (Sn: site A) to a maximum of $6.12 \%$ (Cd: site B). Reported levels of metal release are greatest for Cd (3.33-6.12\%) and Zn (3.12-4.73\%) which is consistent with studies in the literature that identify $\mathrm{Cd}$ and $\mathrm{Zn}$ as pollutants which typically associate most readily with the dissolved phase $[36,37]$.

All metals (with the exception of $\mathrm{Hg}$ ) show the greatest release at site $\mathrm{B}(r=0.59 ; p \leq 0.05)$ indicating that metals stored in sediments at this site are potentially more susceptible to release. Greater potential for the release of metals from sediments at this site could also indicate that sediments are a source of the elevated aqueous metal concentrations also reported at site B (see Section 3.1). Correlation analysis of sediment metal release data with levels of $\mathrm{pH}$ and dissolved organic content (DOC) determined after the experiment does not suggest that any of these parameters are responsible for the variations in metal release reported from sediments except for $\mathrm{Pb}$ and $\mathrm{Ni}$ where an inverse correlation with $\mathrm{pH}(p \leq 0.05 ; r=-0.9)$ exists. Further examination of the sediments regarding their mineral and total organic content composition, sediment $\mathrm{pH}$ and cation exchange capacity may reveal the processes driving this relatively higher release for other metals at this site, but these were not within the scope of the current study. 
Table 2. Overview of the range of concentrations (minimum-maximum) and mean $\left(\mu \mathrm{g} \mathrm{L}^{-1} \pm \mathrm{SD}\right.$ ) total metal concentrations in surface waters determined at five sampling sites together with relevant water quality standards.

\begin{tabular}{|c|c|c|c|c|c|c|c|c|c|c|c|c|c|c|}
\hline \multirow{2}{*}{ Site } & \multicolumn{2}{|r|}{$\mathrm{Cd}$} & \multicolumn{2}{|c|}{$\mathrm{Cu}$} & \multicolumn{2}{|r|}{$\mathrm{Hg}$} & \multicolumn{2}{|r|}{$\mathrm{Ni}$} & \multicolumn{2}{|r|}{$\mathrm{Pb}$} & \multicolumn{2}{|c|}{ Sn } & \multicolumn{2}{|r|}{$\mathrm{Zn}$} \\
\hline & Range & Mean \pm SD & Range & Mean \pm SD & Range & Mean \pm SD & Range & Mean \pm SD & Range & Mean \pm SD & Range & Mean \pm SD & Range & Mean \pm SD \\
\hline A & $0.02-0.15$ & $0.07 \pm 0.10$ & $1.04-27.2$ & $7.73 \pm 10.3$ & $0.02-1.00$ & $0.35 \pm 0.40$ & $0.66-25.9$ & $9.73 \pm 7.90$ & $0.21-3.93$ & $1.54 \pm 1.40$ & $0.10-2.38$ & $0.65 \pm 0.90$ & $1.25-33.3$ & $11.0 \pm 9.90$ \\
\hline$B$ & $0.04-0.44$ & $0.14 \pm 0.10$ & $1.06-28.2$ & $10.4 \pm 10.7$ & $0.01-0.41$ & $0.10 \pm 0.10$ & $7.37-55.1$ & $23.41 \pm 18.8$ & $0.92-13.3$ & $3.75 \pm 4.10$ & $0.07-1.86$ & $0.59 \pm 0.60$ & $7.85-62.7$ & $24.9 \pm 21.2$ \\
\hline$C$ & $0.01-0.35$ & $0.09 \pm 0.10$ & $1.73-32.5$ & $9.68 \pm 11.1$ & $0.01-0.20$ & $0.06 \pm 0.10$ & $5.89-28.9$ & $15.4 \pm 8.20$ & $0.72-4.87$ & $1.87 \pm 1.40$ & $0.09-1.02$ & $0.34 \pm 0.30$ & $6.18-42.4$ & $17.2 \pm 11.8$ \\
\hline D & $0.01-0.33$ & $0.08 \pm 0.10$ & $1.21-46.7$ & $10.14 \pm 16.0$ & $0.01-0.29$ & $0.08 \pm 0.10$ & $5.25-44.6$ & $16.22 \pm 14.4$ & $0.51-3.40$ & $1.68 \pm 0.90$ & $0.09-1.91$ & $0.58 \pm 0.70$ & $5.45-44.9$ & $17.7 \pm 16.7$ \\
\hline E & $0.01-0.39$ & $0.15 \pm 0.10$ & $1.92-27.0$ & $8.73 \pm 9.90$ & $0.01-0.40$ & $0.13 \pm 0.20$ & $4.81-24.2$ & $12.96 \pm 8.10$ & $0.33-4.71$ & $2.20 \pm 1.40$ & $0.06-13.9$ & $2.15 \pm 4.80$ & $5.12-38.3$ & $14.9 \pm 11.4$ \\
\hline UK TAG & \multicolumn{6}{|c|}{$1.00^{\text {(a) }}$} & & & & & & & \multicolumn{2}{|c|}{$14.2^{(b)}$} \\
\hline EQS AA* & \multicolumn{4}{|c|}{$0.25^{\text {(c) }}$} & & & \multicolumn{2}{|c|}{$4.00^{\text {(a) }}$} & \multicolumn{2}{|c|}{$1.20^{\text {(a) }}$} & & & & \\
\hline EQS MAC ** & \multicolumn{2}{|c|}{1.50 (c) } & & & \multicolumn{2}{|c|}{$0.07^{\text {(d) }}$} & & 34.0 & \multicolumn{2}{|c|}{14.0} & & & & \\
\hline
\end{tabular}

Key: * Annual average; ** Maximum allowable concentration; ${ }^{(a)}$ Bioavailable fraction; ${ }^{(b)}$ Bioavailable fraction $10.90 \mu \mathrm{g} \mathrm{L}^{-1}+$ Ambient background concentration $3.3 \mu \mathrm{g} \mathrm{L}^{-1}$ dissolved Zn for River Lee; (c) For Cd and its compounds the EQS values here are for Class $5\left(\geq 200 \mathrm{mg} \mathrm{CaCO}_{3} \mathrm{~L}^{-1}\right)$ as per hardness of water in the Lower Lee catchment; (d) Value for $\mathrm{Hg}$ and its compounds. Text in italics and bold indicates sampling points on tributaries.

Table 3. Overview of the range of concentrations (minimum-maximum) and mean ( $\mu \mathrm{g} \mathrm{g}^{-1} \pm \mathrm{SD}$ ) total metal concentrations in surficial sediments determined at five sampling sites $(n=8)$ together with relevant sediment quality guidelines.

\begin{tabular}{|c|c|c|c|c|c|c|c|c|c|c|c|c|c|c|}
\hline \multirow{2}{*}{ Site } & \multicolumn{2}{|r|}{$\mathrm{Cd}$} & \multicolumn{2}{|r|}{$\mathrm{Cu}$} & \multicolumn{2}{|r|}{$\mathrm{Hg}$} & \multicolumn{2}{|r|}{$\mathrm{Ni}$} & \multicolumn{2}{|r|}{$\mathrm{Pb}$} & \multicolumn{2}{|c|}{ Sn } & \multicolumn{2}{|r|}{$\mathrm{Zn}$} \\
\hline & Range & Mean \pm SD & Range & Mean \pm SD & Range & Mean \pm SD & Range & Mean \pm SD & Range & Mean \pm SD & Range & Mean \pm SD & Range & Mean \pm SD \\
\hline A & $0.47-0.88$ & $0.67 \pm 0.20$ & $32.6-73.7$ & $46.1 \pm 13.3$ & $0.01-1.02$ & $0.19 \pm 0.30$ & $1.34-19.5$ & $13.7 \pm 6.60$ & $50.8-88.8$ & $68.2 \pm 11.4$ & $0.67-7.98$ & $4.66 \pm 3.00$ & 109-219 & $164 \pm 41.6$ \\
\hline B & $0.48-3.15$ & $1.20 \pm 0.90$ & $40.3-150$ & $79.6 \pm 41.9$ & $0.01-1.68$ & $0.53 \pm 0.60$ & $0.01-16.2$ & $5.91 \pm 5.80$ & $105-241$ & $171 \pm 50.6$ & $1.36-73.9$ & $21.4 \pm 24.1$ & 170-606 & $373 \pm 169$ \\
\hline C & $0.18-1.21$ & $0.45 \pm 0.30$ & $35.6-294$ & $91.8 \pm 91.1$ & $0.01-1.32$ & $0.40 \pm 0.51$ & $0.14-18.9$ & $8.88 \pm 5.93$ & $50.0-253$ & $96.2 \pm 68.4$ & $0.55-27.6$ & $13.9 \pm 10.3$ & $94.1-617$ & $231 \pm 164$ \\
\hline $\mathrm{E}$ & $3.72-5.64$ & $5.01 \pm 0.60$ & $108-161$ & $127 \pm 16.3$ & $0.49-1.57$ & $1.07 \pm 0.40$ & $29.0-51.1$ & $38.2 \pm 6.20$ & $169-213$ & $197 \pm 12.9$ & $3.30-23.1$ & $15.9 \pm 6.50$ & $535-665$ & $605 \pm 48.9$ \\
\hline Dutch TV ${ }^{1}$ & \multicolumn{2}{|r|}{0.80} & \multicolumn{2}{|r|}{36.0} & \multicolumn{2}{|r|}{0.30} & \multicolumn{2}{|c|}{35.0} & \multicolumn{2}{|r|}{85.0} & & & \multicolumn{2}{|r|}{140} \\
\hline Dutch IV ${ }^{2}$ & \multicolumn{2}{|r|}{12.0} & \multicolumn{2}{|r|}{190} & \multicolumn{2}{|r|}{10.0} & \multicolumn{2}{|c|}{210} & \multicolumn{2}{|r|}{530} & & & \multicolumn{2}{|r|}{720} \\
\hline Canadian ISQG $^{3}$ & \multicolumn{2}{|r|}{0.60} & \multicolumn{2}{|r|}{35.7} & \multicolumn{2}{|r|}{0.17} & & & \multicolumn{2}{|r|}{35.0} & & & \multicolumn{2}{|r|}{123} \\
\hline
\end{tabular}

${ }^{1}$ Target value-indicate the level that has to be achieved to fully recover the functional properties of the soil/sediment for humans, plant and animal life; ${ }^{2}$ Intervention value-indicate when the functional properties of the soil/sediment for humans, plant and animal life, is seriously impaired or threatened; ${ }^{3}$ Interim sediment quality guideline- represents the concentration below which adverse biological effects are expected to occur rarely; ${ }^{4}$ Probable effect level—defines the level above which adverse biological effects are expected to occur frequently. Text in italics and bold indicates sampling points on tributaries. 
Table 4. Mass percentage of metals released from sediments collected at five different sites into overlying water in laboratory-based batch tests over a $24 \mathrm{~h}$ mixing period.

\begin{tabular}{cccccccc}
\hline Site & $\mathbf{C d}$ & $\mathbf{C u}$ & $\mathbf{H g}$ & $\mathbf{N i}$ & $\mathbf{P b}$ & $\mathbf{S n}$ & $\mathbf{Z n}$ \\
\hline $\mathrm{A}$ & $3.33 \pm 0.36$ & $3.12 \pm 0.04$ & $0.64 \pm 1.93$ & $3.15 \pm 0.39$ & $0.89 \pm 0.14$ & $0.12 \pm 0.11$ & $3.17 \pm 0.02$ \\
$\mathrm{~B}$ & $6.12 \pm 1.25$ & $4.39 \pm 0.01$ & $0.33 \pm 2.67$ & $4.47 \pm 0.16$ & $1.03 \pm 0.01$ & $0.50 \pm 0.08$ & $4.73 \pm 0.10$ \\
$\mathrm{C}$ & $4.00 \pm 0.67$ & $1.95 \pm 0.12$ & $0.33 \pm 1.00$ & $1.99 \pm 0.25$ & $0.52 \pm 0.05$ & $0.14 \pm 0.03$ & $3.12 \pm 0.05$ \\
$\mathrm{D}$ & $4.97 \pm 0.26$ & $2.26 \pm 0.12$ & $0.42 \pm 0.49$ & $3.58 \pm 0.10$ & $0.90 \pm 0.00$ & $0.33 \pm 0.08$ & $3.82 \pm 0.01$ \\
$\mathrm{E}$ & $3.84 \pm 0.11$ & $2.85 \pm 0.04$ & $0.27 \pm 0.29$ & $3.28 \pm 0.05$ & $0.66 \pm 0.01$ & $0.26 \pm 0.02$ & $3.33 \pm 0.01$ \\
\hline
\end{tabular}

\subsection{Integration of Aqueous and Sediment Metal Concentration Data with the Results of Laboratory} Batch Experiments

The reported results (Tables 2 and 3) confirm the expected ability of the urban river sediments at all study sites to concentrate metals relative to the overlying waters [38-40]. However, the metal concentration trends do not necessarily parallel each other in the different phases. Thus, in this study, water samples indicated the highest mean metal concentrations at the two tributary sites: Pymmes Brook (Site B: $\mathrm{Pb}, \mathrm{Ni}$ and $\mathrm{Zn}$ ) and Cobbins Brook (Site C: $\mathrm{Cd}, \mathrm{Cu}, \mathrm{Hg}$ and $\mathrm{Sn}$ ). In contrast, the highest mean sediment metal concentrations were found on the main river at $\mathrm{Site} \mathrm{D}(\mathrm{Cu}, \mathrm{Pb}, \mathrm{Sn} \mathrm{Zn})$ and Site $\mathrm{E}(\mathrm{Cd}, \mathrm{Hg}, \mathrm{Ni})$. Whilst the data ranges reported for sediment and aqueous concentrations varied between sampling dates and sample sites (as indicated by the magnitude of the associated standard deviations), sediment concentration variability was considerably less supporting the use of sediments as a better indicator of, and hence a preferred medium for, monitoring the environmental quality of aquatic systems $[7,8,41]$.

Analysis of the mean water and sediment metal concentrations did not reveal a statistically significant relationship between the two environmental compartments. This demonstrates the complex relationship that exists between metal behaviours within the two matrices. However, whilst mean aqueous metal concentrations did not appear to vary significantly in relation to mean sediment metal concentrations (see Section 3.3), the correlation analysis revealed a relationship between aqueous metal concentrations and the batch test-derived sediment metal release data, particularly during the two wet weather events. For example, aqueous $\mathrm{Zn}$ concentrations correlate with the sediment metal release data during both wet weather events (May 2015 and August 2015; $r=0.910$ and 0.938; respectively; $p \leq 0.05$ (both values)); see Figure 2 for dry weather data and Figure 3 for wet weather data).

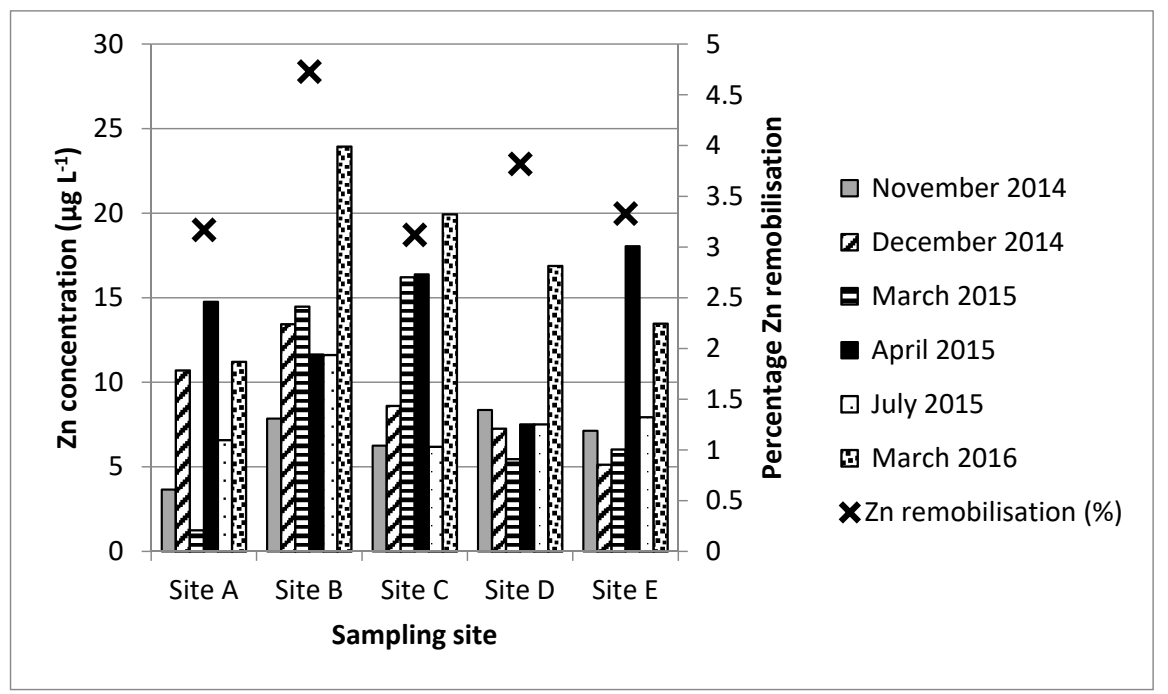

Figure 2. Overview of mean $\mathrm{Zn}$ aqueous concentrations during dry weather events at sites A-E in relation to $\mathrm{Zn}$ sediment remobilisation (\%) determined during laboratory batch tests. 


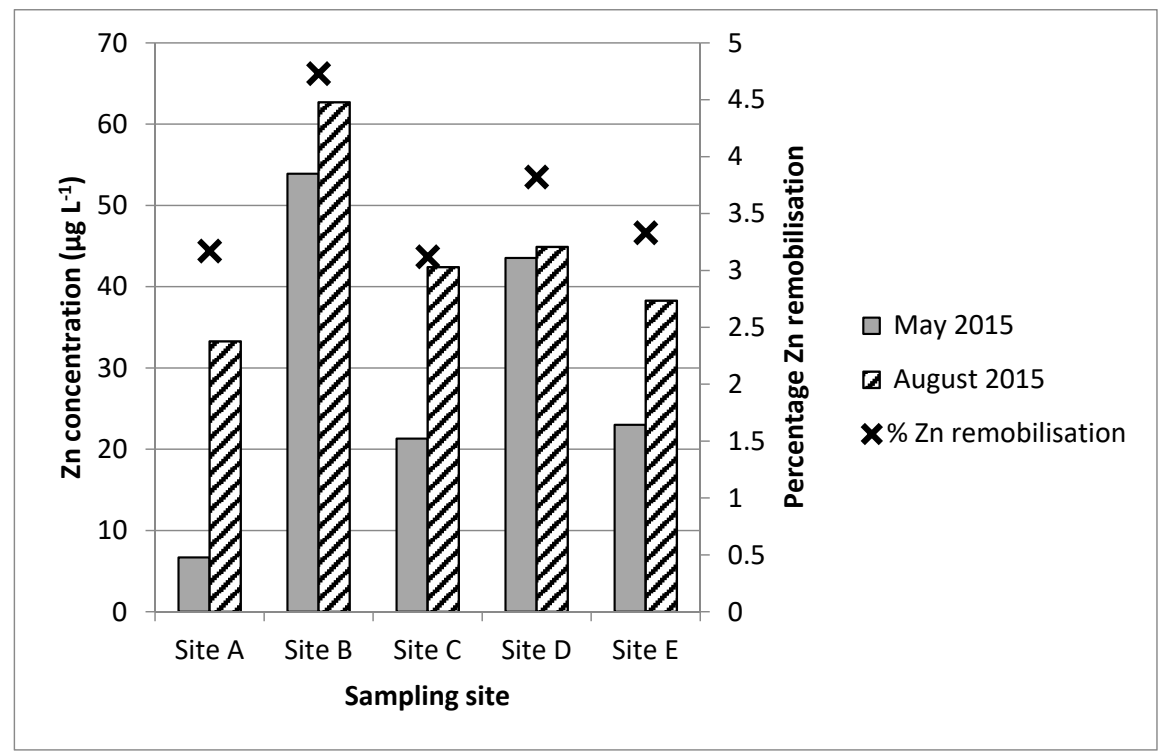

Figure 3. Overview of mean $\mathrm{Zn}$ aqueous concentrations during wet weather events at sites A-E in relation to $\mathrm{Zn}$ sediment remobilisation (\%) determined during laboratory batch tests.

Likewise, positive significant correlations were also evident during the August wet weather event for $\mathrm{Cu}(r=0.928 ; p \leq 0.05)$ and $\mathrm{Pb}(r=0.875 ; p \leq 0.05)$, and for $\mathrm{Hg}$ and Sn during the May wet weather event ( $r=0.93$ and $0.87 ; p \leq 0.05$ both values, respectively). Significant positive correlations were also determined during some of the dry weather events (July 2015; Hg, Zn, Ni), November 2014 (Hg), December 2014 (Cd), and March 2016 (Hg). Whilst the overall pattern is not clear or consistent for all metals, the data does support the suggestion that the aqueous metal water concentrations are influenced by the releasable sediment metal concentrations (as determined from batch tests) during both wet and dry weather conditions in the field. The enhanced flow volumes and flow rates associated with wet weather conditions will encourage the resuspension of sediment and, consequently, the release of previously particulate-associated metals [42], as has been demonstrated in this study under laboratory conditions. The occurrence of positive correlations between aqueous metal and releasable sediment metal concentrations during dry weather could indicate the involvement of other sources of sediment resuspension activities, e.g., accidental spills or localised events, such as disturbance caused by human activities.

\section{Conclusions}

Analysis of water and sediment metal concentrations showed that tributaries originating from heavily urbanised environments contribute to the heavy metal load of the River Lee. Metals transported into the river are likely to be stored in the sediment and, as shown by the batch tests, can be released into the overlying water, resulting in exceedances of water quality standards. The proportions of metals released varied with different weather conditions and site specific parameters. Zinc and $\mathrm{Hg}$ were found to be released most frequently, based on the correlation between sediment release potential and water concentrations, with concentrations of Zn consistently exceeding the UK TAG standards during correlated events and are, therefore, of particular concern. The results of this study highlight the importance of monitoring sediment as well as water quality and further analysis of sediment properties, water parameters, and chemical speciation of metals can strengthen the capacity of predicting pollutant release from contaminated sediments into the overlying water body. The findings are of relevance to all urban rivers in receipt of point and diffuse pollution, and of particular pertinence to those requiring remediation to achieve the environmental objectives of the EU Water Framework Directive [1]. 
Author Contributions: L.L., M.R. and D.W. conceived and designed the sampling programme and laboratory experiments; L.A. performed the experiments; M.R. and D.W. analyzed the data; L.L. wrote the paper.

Conflicts of Interest: The authors declare no conflict of interest.

\section{References}

1. Directive 2000/60/EC of the European Parliament and of the Council of 23 October 2000 Establishing a Framework for Community Action in the Field of Water Policy. Available online: http:/ / eur-lex.europa. eu/LexUriServ / LexUriServ.do?uri=CELEX:32000L0060:EN:HTML (accessed on 13 February 2017).

2. EU Priority Substances Directive. Directive 2013/39/EC of the European Parliament and of the Council of 12 August 2013 Amending Directives 2000/60/EC and 2008/105/EC as Regards Priority Substances in the Field of Water Policy. 2013. Available online: http:/ / eur-lex.europa.eu/LexUriServ/LexUriServ.do?uri=OJ: L:2013:226:0001:0017:EN:PDF (accessed on 23 March 2017).

3. Water for Life and Livelihoods. Part 1. Thames River Basin District. River Basin Management Plan. p. 113. Environment Agency: Bristol, UK. Available online: https:/ /www.gov.uk/government/uploads / system/uploads/attachment_data/file/500548/Thames_RBD_Part_1_river_basin_management_plan.pdf (accessed on 23 March 2017).

4. Snook, D.L.; Whitehead, P.G. Water quality and ecology of the River Lee: Mass balance and a review of temporal and spatial data. Hydrol. Earth Syst. Sci. 2004, 81, 636-650. [CrossRef]

5. Ellis, J.B.; Mitchell, G. Urban diffuse pollution: Key data information approaches for the Water Framework Directive. Water Environ. J. 2006, 20, 19-26. [CrossRef]

6. Gardner, M.; Jones, V.; Comber, S.; Scrimshaw, M.D.; Garcia, T.C.; Cartmell, E.; Lester, J.; Ellor, B. Performance of UK wastewater treatment works with respect to trace contaminants. Sci. Total Environ. 2013, 456, 359-369. [CrossRef] [PubMed]

7. Owens, P.N.; Walling, D.E.; Carton, J.; Meharg, A.A.; Wright, J.; Leeks, G.J.L. Downstream changes in the transport and storage of sediment-associated contaminants (P, Cr and PCBs) in agricultural and industrialised drainage basins. Sci. Total Environ. 2001, 266, 177-186. [CrossRef]

8. Taylor, K.; Owens, P.O.; Batalla, R.J.; Garcia, C. Sediment and Contaminant Sources and Transfers in Rivers Basins. In Sustainable Management of Sediment Resources, Sediment Management at the River Basin Scale; Owens, P.N., Ed.; Elsevier Science: Amsterdam, The Netherlands, 2008; Chapter 4, pp. 83-135, ISBN 978-0-444-51961-0.

9. Sharley, D.J.; Sharp, S.M.; Bourgues, S.; Pettigrove, V.J. Detecting lon-term temporal trends in sediment-bound metals from urbanised catchments. Environ. Pollut. 2016, 219, 705-713. [CrossRef] [PubMed]

10. Blecken, G.-T.; Rentz, R.; Malmgren, C.; Ohlander, B.; Viklander, M. Stormwater impact on urban waterways in a cold climate: Variations in sediment metal concentrations due to untreated snowmelt discharge. J. Soils Sediments 2012, 12, 758-773. [CrossRef]

11. De Carlo, E.H.; Anthony, S.S. Spatial and temporal variability of trace element concentrations in a subtropical watershed, Honolulu, Hawaii. Appl. Geochem. 2002, 17, 475-492. [CrossRef]

12. Komínková, D.; Nabelkova, J.; Vitvar, T. Effects of combined sewer overflows and storm water drains on metal bioavailability in small urban streams (Prague metropolitan area, Czech Republic). J. Soils Sediments 2016, 16, 1569-1583. [CrossRef]

13. Sebakira, K.; Origa, H.O.; Basamba, T.A.; Mutumba, G.; Kakudidi, E. Assessment of heavy metal pollution in the urban stream sediments and its tributaries. Int. J. Environ. Sci. Technol. 2010, 7, 435-446.

14. Sutherland, R.A. Bed sediment-associated trace metals in an urban stream, Oahu, Hawaii. Environ. Geol. 2000, 39, 611-627. [CrossRef]

15. Lundy, L.; Wade, R. Integrating sciences to sustain urban ecosystem services. Prog. Phys. Geogr. 2011, 35, 653-669. [CrossRef]

16. Crane, M. Proposed development of sediment quality guidelines under the European Water Framework Directive: A critique. Toxicol. Lett. 2003, 142, 195-206. [CrossRef]

17. Turner, J.N.; Brewer, P.A.; Macklin, M.G. Fluvial-controlled metal and As mobilisation, dispersal and storage in the Rio Guadiamar, SW Spain and implications for long-term contaminant fluxes to the Doñana wetlands. Sci. Total Environ. 2008, 394, 144-161. [CrossRef] [PubMed] 
18. Lim, W.Y.; Ahmad, Z.A.; Mohamad, P.Z. Spatial variability of metals in surface water and sediment in the Langat River and geochemical factors that influence their water-sediment interactions. Sci. World J. 2012, 2012, 652150. [CrossRef] [PubMed]

19. Weiner, E. Applications of Environmental Aquatic Chemistry: A Practical Guide; CRC Press: New York, NY, USA, 2013.

20. Macklin, M.G.; Brewer, P.A.; Hudson-Edwards, K.A.; Bird, G.; Coulthard, T.J.; Dennis, I.A.; Lechler, P.J.; Miller, J.R.; Turner, J.N. A geomorphological approach to the management of rivers contaminated by metal mining. Geomorphology 2006, 79, 423-447. [CrossRef]

21. Canadian Council of Ministers of the Environment. 2002; Canadian Environmental Quality Guidelines. Winnipeg, Canada. Available online: http://www.ccme.ca/en/resources/canadian_environmental_quality_ guidelines/ (accessed on 27 March 2017).

22. Ministry of Housing, Spatial Planning and the Environment. Dutch Target and Intervention Values (the New Dutch List). Amsterdam, The Netherlands, 2000. Available online: https:/ /www.esdat.net/Environmental\% 20Standards/Dutch/annexS_I2000Dutch\%20Environmental\%20Standards.pdf (accessed on 27 March 2017).

23. Ministry of Ecology and Sustainable Development and Water Agencies. Water Quality Assessment System (SEQ-Eau). Version 2. 2003. Available online: http://rhin-meuse.eaufrance.fr/IMG/pdf/grilles-seq-eau-v2. pdf) (accessed on 28 March 2017).

24. Duodu, G.O.; Goonetilleke, A.; Ayoko, G.A. Comparison of pollution indices for the assessment of heavy metals in Brisbane River sediment. Environ. Pollut. 2016, 219, 1077-1091. [CrossRef] [PubMed]

25. OECD. OECD Guidelines for the Testing of Chemicals, Section 1. Test No. 106: Adsorption-Desorption Using a Batch Equilibrium Method. 2002, p. 44. Available online: http://www.oecd-ilibrary. org/docserver/download /9710601e.pdf?expires=1490114156\&id=id\&accname=guest\&checksum= 488BEA5632E20587A1AC85A72255A54D (accessed on 21 March 2017).

26. US EPA. Method 3015A (2007) Microwave Assisted Acid Digestion of Aqueous Samples and Extracts. Available online: https://www.epa.gov/sites/production/files/2015-12/documents/3015a.pdf (accessed on 21 March 2017).

27. US EPA. Method 3051A (2007) Microwave Assisted Acid Digestion of Sediments, Sludges, Soils and Oils. Available online: https://www.epa.gov/sites/production/files/2015-12/documents/3051a.pdf (accessed on 21 March 2017).

28. Paul, M.; Meyer, J. Streams in the urban landscape. Ann. Rev. Ecol. Syst. 2001, 32, 333-365. [CrossRef]

29. Faisal, B.M.R.; Majumder, R.K.; Uddin, M.J.; Halim, M.A. Studies on heavy metals in industrial effluent, river and groundwater of Savar industrial area, Bangladesh. Int. J. Geomat. Geosci. 2014, 5, 182-191.

30. Sörme, L.; Lagerkvist, R. Sources of heavy metals in urban wastewater in Stockholm. Sci. Total Environ. 2002, 298, 131-145. [CrossRef]

31. Environmental Agency. Report on Diffuse Water Pollution in England and Wales: The Unseen Threat to Water Quality. London, UK. Available online: http://www.fwr.org/WQreg/Appendices/EA_Diffuse_ Pollution_Report_geho0207bzlvee_1773088.pdf (accessed on 21 March 2017).

32. Baccini, P.; Brunner, P.H. Metabolism of the Anthroposphere: Analysis, Evaluation, Design, 2nd ed.; MIT Press: Cambridge, MA, USA, 2012.

33. UK TAG. Environmental Standards and Conditions (Phase 1): Final Report. United Kingdom Technical Advisory Group on the Water Framework Directive. (SR1-2006). 2008. Available online: https:/ / www.wfduk.org/sites/default/files/Media/Environmental\%20standards/Environmental\% 20standards\%20phase\%201_Finalv2_010408.pdf (accessed on 21 March 2017).

34. Crane, M.; Kwok, K.W.H.; Wells, C.; Whitehouse, P.; Lui, G. Use of field data to support European Water Framework Directive Quality Standards for dissolved metals. Environ. Sci. Technol. 2007, 41, 5014-5021. [CrossRef] [PubMed]

35. Comber, S.D.W.; Merrington, G.; Sturdy, L.; Delbeke, K.; van Assche, F. Copper and zinc water quality standards under the EU Water Framework Directive: The use of a tiered approach to estimate the levels of failure. Sci. Total Environ. 2008, 403, 12-22. [CrossRef] [PubMed]

36. Hem, J.D. Chemistry and occurrence of cadmium and zinc in surface water and groundwater. Water Resour. Res. 1972, 8, 661-679. [CrossRef]

37. Morrison, G.M.P.; Revitt, D.M.; Ellis, J.B.; Svenson, G.; Balmer, P. Variations of dissolved and suspended solid heavy metals through an urban hydrograph. Environ. Technol. Lett. 1984, 5, 313-318. [CrossRef] 
38. Salem, Z.B.; Capelli, N.; Laffray, X.; Elise, G.; Ayadi, H.; Aleya, L. Seasonal variation of heavy metals in water, sediment and roach tissues in a landfill draining system pond (Etueffont, France). J. Ecol. Eng. 2014, 69, 25-37. [CrossRef]

39. Omar, H.E.D.M. Seasonal variation of heavy metals accumulation in muscles of the African Catfish Clarias gariepinus and in River Nile water and sediments at Assiut Governorate, Egypt. J. Biol. Earth Sci. 2013, 3, B236-B248.

40. Ali, M.; Abdel-Satar, A. Studies of some heavy metals in water, sediment, fish and fish diets in some fish farms in El-Fayoum province, Egypt. J. Aquac. Res. 2005, 31, 261-273.

41. Agunbiade, F.O.; Olu-Owolabi, B.I.; Adebowale, K.O. Seasonal and spatial variations analysis of pollution status of Ondo coastal environment Nigeria using principal component analysis. Geochem. J. 2010, 44, 89-98. [CrossRef]

42. Li, H.; Shi, A.; Li, M.; Zhang, X. Effect of $\mathrm{pH}$, temperature, dissolved oxygen, and flow rate of overlying water on heavy metals release from storm sewer sediments. J. Chem. 2013, 2013, 434012. [CrossRef]

(C) 2017 by the authors. Licensee MDPI, Basel, Switzerland. This article is an open access article distributed under the terms and conditions of the Creative Commons Attribution (CC BY) license (http://creativecommons.org/licenses/by/4.0/). 